Georgia State University

ScholarWorks @ Georgia State University

\title{
Amygdala and Nucleus Accumbens Activation to Emotional Facial Expressions in Children and Adolescents at Risk for Major Depression
}

\author{
Christopher S. Monk \\ University of Michigan - Ann Arbor \\ Rachel G. Klein \\ Eva H. Telzer \\ University of California - Los Angeles \\ Salvatore Mannuzza \\ Nathan S. Kline Institute for Psychiatric Research \\ John L. Moulton III
}

See next page for additional authors

Follow this and additional works at: https://scholarworks.gsu.edu/psych_facpub

Part of the Psychology Commons

\section{Recommended Citation \\ Monk, Christopher S.; Klein, Rachel G.; Telzer, Eva H.; Mannuzza, Salvatore; Moulton, John L. III; Guardino, Mary; Masten, Carrie L.; McClure, Erin B.; Fromm, Stephen; Pine, Daniel S.; and Ernst, Monique, "Amygdala and Nucleus Accumbens Activation to Emotional Facial Expressions in Children and Adolescents at Risk for Major Depression" (2008). Psychology Faculty Publications. 138. \\ https://scholarworks.gsu.edu/psych_facpub/138}

This Article is brought to you for free and open access by the Department of Psychology at ScholarWorks @ Georgia State University. It has been accepted for inclusion in Psychology Faculty Publications by an authorized administrator of ScholarWorks @ Georgia State University. For more information, please contact scholarworks@gsu.edu. 


\section{Authors}

Christopher S. Monk, Rachel G. Klein, Eva H. Telzer, Salvatore Mannuzza, John L. Moulton III, Mary Guardino, Carrie L. Masten, Erin B. McClure, Stephen Fromm, Daniel S. Pine, and Monique Ernst 
Word count: 4862

Number of Tables: 2

Number of Figures: 3

Amygdala and Nucleus Accumbens Activation to Emotional Facial Expressions in Children and Adolescents at Risk for Major Depression

Christopher S. Monk, Ph.D., Rachel G. Klein, Ph.D., Eva H. Telzer, B.A., Elizabeth A. Schroth, B.A., Salvatore Mannuzza, Ph.D., John L. Moulton III, Ph.D., Mary Guardino, B.A., Carrie L. Masten, M.A., Erin B. McClure, Ph.D., Stephen Fromm, Ph.D., R. James R. Blair, Ph.D., Daniel S. Pine, M.D., Monique Ernst, M.D., Ph.D.

From the Department of Psychology, the Center for Human Growth and Development, and the Department of Psychiatry, University of Michigan, Department of Psychiatry, New York University, New York, NY 10016, Department of Psychology, University of California, Los Angeles 90095, Department of Psychology, Georgia State University, Atlanta, GA 30302, Mood and Anxiety Disorders Program, NIMH, NIH, DHHS, Bethesda, MD 20892, Nathan S. Kline Institute for Psychiatric Research, Orangeburg, NY 10962. Address correspondence to Dr. C.S. Monk, Department of Psychology, 530 Church Street, University of Michigan, Ann Arbor, MI 48109, csmonk@umich.edu. Part of this work was presented at the Society of Biological Psychiatry, Atlanta, GA, May 2005 and at the Society for Research in Child Development, Boston, MA, March 2007. 
None of the authors have competing interests related to this study.

This research was supported in part by the National Institute of Mental Health (K22 MH068017 to C.S.M and R01 MH59171 to R.G.K.), the National Alliance for Research on Schizophrenia and Depression (D.S.P.) and the National Institute of Mental Health Intramural Research Program.

We thank the families who participated. We also thank Drs. K. Towbin, A. Zametkin, and J. Cameron for medical oversight, A. Rakow for administrative support and $\mathrm{H}$. Iwamoto for programming. 


\begin{abstract}
Objective. Offspring of parents with major depressive disorder (MDD) face three-fold higher risk for MDD than offspring without a family history. Although MDD is a major cause of morbidity and mortality, neural correlates of risk for MDD remain poorly understood. This study compares amygdala and nucleus accumbens activation in children and adolescents at high and low risk for MDD under varying attentional and emotional conditions. Methods. Thirty-nine juveniles, 17 offspring of parents with MDD (high-risk group) and 22 offspring of parents without histories of MDD, anxiety or psychotic disorders (low-risk group) completed a functional magnetic resonance imaging study. During imaging, subjects viewed faces that varied in intensity of emotional expressions across blocks of trials; while attention was unconstrained (passive viewing), and constrained (rate nose width on face; rate subjective fear while viewing face). Results. When attention was unconstrained, high-risk, relative to lowrisk, subjects showed greater amygdala and nucleus accumbens (NAcc) activation to fearful faces, and lower NAcc activation to happy faces ( $p$ values $<.05$, small volume corrected for the amygdala and NAcc). No group differences emerged in amygdala or NAcc activation during constrained attention. Exploratory analysis showed that constraining attention was associated with greater medial prefrontal cortex activation in the high-risk than low-risk group. Conclusions. Amygdala and NAcc responses to affective stimuli may reflect vulnerability for MDD. Constraining attention may normalize emotion-related neural function, possibly via engagement of the medial prefrontal cortex; face-viewing with unconstrained attention may engage aberrant processes associated with risk for MDD.
\end{abstract}




\section{Introduction}

Offspring of parents with major depressive disorder (MDD) face three-fold greater risk for MDD than offspring without such family histories ${ }^{1}$. Neural correlates of this familial risk have been minimally studied. A full understanding of neural correlates of MDD risk requires the study of at-risk individuals before they have passed the developmental period of risk. Since MDD typically first emerges in early adulthood ${ }^{2}$, data from at-risk adults, without histories of MDD, may reflect neural correlates of resilience as opposed to risk. No prior study has examined neural correlates of risk for MDD in unaffected juvenile offspring of MDD parents through functional magnetic resonance imaging (fMRI).

Since MDD is a disorder of emotion, neural correlates may be best understood in the context of emotional processes. For example, adults with MDD show perturbed responses to motivationally-salient stimuli. Clinically, they ruminate more about negative events and report less satisfaction from rewards than healthy peers ${ }^{3,4}$. In the laboratory, they show perturbed information processing of motivationally-salient stimuli ${ }^{5-}$ 8

The amygdala and nucleus accumbens (NAcc) respond to negative and positive signals. The amygdala is a rapid detector of cues impacting well being ${ }^{9}$. Across various species, the amygdala responds to positive and, most reliably, negative stimuli, such as fearful faces ${ }^{9-13}$. The NAcc, a structure within the ventral striatum, is most consistently responsive to rewards, like money and happy facial displays ${ }^{14-20}$. The NAcc also regulates motor responses to aversive stimuli ${ }^{19}$. Together the amygdala and NAcc mediate detection and reaction to motivating stimuli. 
MDD patients show perturbed activation in these structures. In adult MDD, fearful and sad faces elicit greater amygdala activation than in comparisons ${ }^{21,22}$. Data are less consistent in youth. In a small report, fearful faces produced relatively decreased amygdala activation in MDD girls ${ }^{23}$. In contrast, a larger study found enhanced amygdala activation in adolescents with MDD relative to healthy adolescents during incidental memory encoding of faces ${ }^{24}$. In adults with MDD, there is relatively heightened activation in the NAcc to sad faces ${ }^{22,25}$ and reduced activation to happy faces $^{22}$. Moreover, youth with MDD showed reduced activation in multiple regions including the striatum in response to a monetary reward ${ }^{26}$. These studies have examined MDD patients rather than individuals at risk. There are no reports of amygdala or NAcc correlates of familial risk for MDD. However, relatedly, research in adults has linked amygdala function to genetic variation. Individuals with short alleles on the serotonin transporter gene are at increased risk for $\mathrm{MDD}^{27}$ and show hyperactivation of the amygdala in response to fearful faces ${ }^{28}$.

The present study uses fMRI to examine juvenile offspring of MDD and healthy adults, while they viewed faces varying in intensity of happy, neutral, and fearful expressions. Rather than solely presenting prototypical expressions, we incrementally varied affective intensity with morphing software to optimize the detection of differences in neural responses ${ }^{29}$. Based on prior work, we probed the amygdala and NAcc ${ }^{21-}$ $25,28,30$. We used happy faces to engage reward processing, and fearful faces to engage threat processing. We used fearful faces, as opposed to angry or sad faces, because fearful faces reliably activate the amygdala ${ }^{9-11,31}$. Furthermore, as noted above, 
neuroimaging investigations of genetic-based risk for MDD in adults yield reliable between-group differences in amygdala activation with fearful faces ${ }^{28}$.

Brain activation is also influenced by attention and cognition. Tasks with low cognitive demands, such as passive viewing of emotional stimuli, preferentially engage subcortical neural circuits ${ }^{10,11,32}$. On such tasks, adults with MDD show greater striatal and amygdala activation than comparisons ${ }^{22}$. Tasks with greater cognitive demands do not engage these structures consistently ${ }^{10,11,32}$. In a prior study, behavioral responses of offspring of MDD parents and comparisons to face-processing tasks did not differ ${ }^{33}$. The normal behavioral performance of juveniles at risk for MDD indirectly suggests that cognitive attentional demands may normalize neural perturbations in at-risk offspring. Therefore, we hypothesized that high-risk offspring, relative to low-risk offspring, would show (1) greater activation in the amygdala and NAcc in response to fearful faces, and (2) less activation in the NAcc to happy faces. Moreover, we hypothesized (3) that these differences would be more pronounced in low relative to high demand cognitive conditions.

\section{Methods}

\section{Participants}

The NIMH and New York University School of Medicine Institutional Review Boards approved the procedures; written informed consent was acquired from parents and offspring aged 18 years. Offspring below 18 years of age signed assents. 
Participants consisted of 17 offspring of parents with MDD (high-risk group) and 22 comparisons (low-risk group). High-risk status was based upon lifetime history of major depression in at least one parent.

Parents with MDD had been patients at mood and anxiety disorder clinics. They received the Structured Clinical Interview for DSM-III-R (SCID) ${ }^{34}$ by trained clinicians. Parents of low-risk offspring were similarly evaluated and found to be free of a lifetime history of anxiety, mood or psychotic disorders.

Offspring were ages 10 through18 years, with IQ's greater than 70. Offspring were evaluated for lifetime mental disorders through direct interviews and interviews with parents about the offspring, by blind trained clinicians using the Parent as Respondent Informant Schedule (PARIS) interview ${ }^{35}$. A diagnosis required either the parent or offspring report to confirm full diagnostic criteria. Exclusion criteria for all offspring included any lifetime history of MDD, any current psychiatric disorder, and current use of any psychoactive substance. While all offspring with current psychopathology were excluded, those with past disorders (except for MDD) were not. Pubertal status was not ascertained.

Diagnostic interviews of parents with depression and their offspring were conducted in New York. Interviews of parents without depression and their offspring were conducted either in New York or Maryland.

\section{Task Procedures}

All fMRI data were collected in Maryland. fMRI probed brain function while subjects viewed faces that varied in intensity of happy or fearful expression, and neutral 
faces. Specifically, the fearful or happy face was morphed with the neutral face of the same model in $25 \%$ increments $^{29}$. Subjects viewed 10 types of facial displays: $100 \%$ happy, 75\% happy/25\% neutral, 50\% happy/50\% neutral, 25\% happy/75\% neutral, $100 \%$ neutral, $25 \%$ fearful/ $75 \%$ neutral, $50 \%$ fearful $/ 50 \%$ neutral, $75 \%$ fearful $/ 25 \%$ neutral, $100 \%$ fearful, and exaggerated fear (150\%) (sample faces are provided in Figure 3). Facial displays were presented in random order across subjects. By parametrically modulating the faces across levels of expression, the degree of facial emotion and brain activation can be correlated.

Subjects viewed 80 different faces ( 8 models by 10 levels of emotion) for a total of three viewings, once in each of three attention conditions (described below). Each attention condition was presented in eight blocks of ten pictures each, from the 80 picture set. The order of the three attention conditions was randomized across subjects, and stimuli were randomized across subjects and across blocks. Faces were displayed for 3 seconds with inter-trial intervals varying between 750-1250 ms.

Facial expression varied randomly from trial to trial (event-related) and the attention condition alternated every 10 trials (block). During face viewing, subjects alternated across three attention conditions ${ }^{11}$. In one condition, subjects passively viewed the faces (attention was unconstrained). In another condition, subjects attended to their subjective fear while viewing the emotional and neutral faces. In the third attention condition, subjects attended to a non-emotional feature of the face (nose width). Subjects were cued to the condition with an instruction screen that appeared for 3 seconds. For the passive viewing condition, the instructions stated, "Just look straight ahead. Do not rate the next set of faces." For subjective fear, subjects were directed to 
press a 5-key button box, responding to, "How afraid are you? 1. Not at all. 2. Just barely. 3. A little. 4. Very 5. Extremely." For nose width, subjects were directed to press a 5-key button box to indicate, "How wide is the nose? 1. Not at all. 2. Just barely. 3. A little. 4. Very wide 5. Extremely wide."

Before scanning, a practice session trained subjects until they demonstrated appropriate performance.

Neuroimaging Procedures and Analyses

We used a GE Signa 3-tesla scanner to acquire 29 interleaved $3.3 \mathrm{~mm}$ axial slices, parallel to the AC-PC [echo-planar single shot gradient echo $\mathrm{T}^{*}$ weighting ( $\mathrm{TR}=2300 \mathrm{~ms} ; \mathrm{TE}=23 \mathrm{~ms} ; \mathrm{FOV}=240 \mathrm{~mm} ; 64 \times 64$ matrix; 3.3×3.75×3.75 mm voxel)]. High-resolution T1-weighted volumetric scans used an MP-RAGE [180.10 mm axial slices; FOV=256 mm, NEX=1, TR=11.4 ms, TE=4.4 ms; matrix=256×256; TI=300 ms, bandwidth $130 \mathrm{~Hz} /$ pixel=33 kHz for 256 pixels in-plane resolution $\left.=1 \mathrm{~mm}^{3}\right]$.

Functional imaging data were analyzed using SPM2. Data underwent slice timing correction to adjust for temporal differences in slice acquisition within each volume. Data were motion corrected to the first functional volume and spatially normalized to a Montreal Neurological Institute T1-weighted template image. The normalization of juvenile brains to a standard brain template is considered valid ${ }^{36}$. Data were then smoothed with a $6 \mathrm{~mm}$ full-width at half-maximum Gaussian kernel.

Functional data were analyzed first at the individual subject level and then at the group level using the general linear model. At the subject level, a design matrix was specified for each subject using one basis function per condition. The regressors were 
derived from a 3-s rectangular pulse that was convolved with a synthetic hemodynamic response function from SPM2. Regression coefficients corresponding to the conditions were estimated from each subject's blood oxygenation level dependent response using the design matrices. With these coefficients, parametric contrasts were generated within each attention condition, by assigning weights to each face depending on the intensity of happiness or fear expressed ${ }^{29,37}$. The linear trend analysis modeled responses from happy to fearful (including neutral). Specifically, a linear trend analysis from happy-to-fearful faces, using all data, compared neural changes as a function of changing stimulus intensity.

Next, the individual subject parametric contrasts were submitted to random effects group level analyses. We used a small volume correction procedure with a threshold of $p<.05^{38}$ with regions of interests for the amygdala and NAcc. Boundaries for these structures are described elsewhere ${ }^{11,14}$. As a first step, we performed an Ftest on the two risk groups, the three attention conditions, and the parametrically varied faces. This provides an omnibus test of the hypothesis concerning group-by-attentionby-face-emotion interactions for the amygdala and NAcc. The overall $F$ test was followed by $t$-tests on the parameterized emotional faces for the three attention conditions separately, to identify the factors that contributed significantly to the betweengroup differences $^{29}$. Finally, to further characterize the results, and to make it possible to relate them to non-parameterized emotional face studies, we conducted post-hoc $t$ tests on the non-chimeric faces (i.e., 100\% happy, neutral, 100\% fear) using the peak voxels of activation from the $t$-tests of the parameterized faces. 


\section{Behavioral Data Analyses}

Behavioral responses of fear and nose ratings as well as reaction times were submitted to repeated-measures ANOVAs. Responses that occurred after $3 \mathrm{~s}$ were not recorded. Greenhouse-Geisser corrections for violations of sphericity were applied when necessary.

\section{Results}

Sample characteristics

The high-risk group, 9 males and 8 females, had a mean age of 14.3 (2.1), and mean IQ of 102.9 (13.4). The low risk group, 10 males and 12 females, had a mean age of 13.9 (2.5) and mean IQ of 105.8 (10.0). There were no group differences. High-risk offspring were recruited from a larger study at the New York University Child Study Center of the biology of risk for anxiety and depressive disorders. Nine low-risk comparisons were drawn from the larger study and, to reduce travel costs, 13 additional comparison subjects were recruited from Maryland.

Of the high-risk offspring, 10/17 (59\%) had a past history of an anxiety disorder, $2(1.2 \%)$ had a previous history of attention-deficit/hyperactivity disorder (ADHD) one with oppositional defiant disorder (ODD). Of the low-risk comparisons, $3 / 22(14 \%)$ had a history of an anxiety disorder. Separate analyses were conducted with the 26 low and high-risk subjects without past anxiety and ADHD/ODD (see Supplement).

Hypothesis 1: high-risk offspring, relative to low-risk comparisons, show significantly greater activation in the amygdala and NAcc in response to fearful faces 
As noted above, a three step analytic process tested this hypothesis. First, the overall $F$-test revealed significant activation differences bilaterally in the amygdala and NAcc between the high and low risk groups (Table 1A; Figure 1). Second, separate $t$ tests for each of the three attention conditions, using linear trend analyses, indicated that, in the passive viewing condition, high-risk, relative to low-risk, offspring showed greater bilateral activation in the amygdala and NAcc to the more fearful faces (Table 1B; Figure 2). To illustrate these associations, contrast values across the facial expressions are plotted (Figure 3). Third, post-hoc $t$-tests were conducted to characterize group differences within passive viewing. Relative to low-risk, high-risk offspring showed greater bilateral amygdala and nucleus accumbens activation during the passive viewing of $100 \%$ fearful faces than neutral faces (Table 1C).

Hypothesis 2: high-risk offspring, relative to low-risk comparisons, show significantly less activation in the NAcc to happy faces

Compared to low-risk juveniles, high-risk subjects had less bilateral NAcc activation during passive viewing of happy faces (100\%) than neutral faces (Table 1C; Figure 3).

Hypothesis 3: There is an interaction between risk status and attention condition on amygdala and NAcc activation such that increased amygdala and NAcc activation during passive viewing of fearful faces in the high risk group is significantly reduced by attentional demands of the cognitive tasks. 
To test this hypothesis, we performed an interaction analysis of the passive viewing condition and each attention condition (i.e., passive viewing vs. subjective fear, and passive viewing vs. nose width) with the linear trend analysis. Direct group contrasts showed that the increase in bilateral amygdala and NAcc activation during passive viewing relative to the constrained attention conditions was greater in the highrisk than low-risk offspring (Table 2).

Within the high-risk offspring, there was greater activation bilaterally in the amygdala and NAcc during passive viewing than during rating of fear and of nose width (Table 2). Within the low risk group, there were no activation differences between passive viewing and the active attention conditions. These findings suggest that the attention conditions may engage other structures, such as areas within the prefrontal cortex (PFC) that are thought to inhibit abnormal activation in the amygdala and NAcc. If so, we would expect high-risk subjects to show greater PFC activation to fear faces in the two attention-constraining tasks compared to low-risk subjects. Exploratory analyses yielded results consistent with this prediction. Compared to low-risk youth, high risk subjects showed significantly greater medial PFC activation when we combined the two attention conditions (subjective fear and nose width rating) and examined group differences to fearful faces, $t(37)=2.91, p=.003$ uncorrected, cluster size $=951, x y z$ coordinates $=-2340$. This was the only area of activation that surpassed a threshold of .05 uncorrected. No group differences were found in this area when attention was unconstrained.

\section{Additional Findings}


Further analyses addressed six additional considerations. First, analyses of task performance indicated that subjects performed as expected (i.e., subjects reported little to no subjective fear to happy faces and higher subjective fear to fearful faces) in both risk groups and no group differences (Supplement Table 1). Second, we examined whether group differences in fMRI results remained when subjects with previous anxiety were removed. The same amygdala and NAcc group differences emerged (Supplement Table 2A). Third, we evaluated whether the removal of the two high risk offspring with past diagnoses of ADHD and ODD affected the results.. Results were unchanged, with one minor exception (Supplement Table 2B). Namely, group differences in right amygdala activation during passive viewing of fearful faces became a trend when the small volume correction was applied $(p=.065)$. Fourth, Figure 3 fails to document amygdala activation in low-risk juveniles to fearful faces in one specific contrast. In supplemental analyses for other contrasts, expected amygdala activation to fear-faces in both low and high-risk juveniles was found, with no between-group differences (Supplement Table 3). Fifth, we found no evidence that activation differed as a function of gender, but subgroups were small. Sixth, age did not relate to activation linearly or curvilinearly.

\section{Discussion}

To our knowledge, this is the first study to examine amygdala and NAcc correlates of familial risk for MDD. Three principal findings emerged. First, offspring at high risk for MDD, relative to those at low-risk, showed greater amygdala and NAcC activation to fearful faces. Second, high-risk, relative to low-risk, offspring evidenced 
less NAcc activation to happy faces. Third, group differences in the amygdala and NAcc to emotional faces were found only during passive viewing and not during constrained attention. Exploratory analysis indicated that constraining attention recruited the medial PFC to a greater degree in the high-risk than low-risk group. This may possibly account for the normal amygdala and NAcc activation when attention was constrained.

The finding that the risk groups differed only during passive viewing suggests that neural processes may be regulated, in part, by attention in those at high risk for MDD. When attention is constrained, responding is comparable in high- and low-risk subjects. Thus, constraining attention may mobilize top-down cortical systems that normalize function in subcortical circuits ${ }^{10,11}$. This possibility is suggested by the finding that attention tasks engaged greater medial PFC activation to fearful faces in the highrisk than low-risk offspring. Meanwhile, the passive viewing condition may allow the expression of neural and related mental processes, such as rumination, that reveal aberrant neural activation associated with MDD vulnerability.

Findings in the present study are consistent with adult neuroimaging findings in MDD patients, but differ from a small study ${ }^{23}$, in which 5 girls with MDD, ages 8-16, showed attenuated amygdala activation to fearful faces. Sampling and methodological differences may account for discrepant findings. Among these, the previous study used a block design in which a specific facial expression was presented repeatedly at a high rate. Therefore, reduced amygdala activation may have been due to amygdala habituation to repeated presentation of fearful faces ${ }^{39}$. In this study, the presentation of facial expressions changed from trial to trial, minimizing habituation. 


\section{Limitations}

Although there was a strong rationale for studying fearful faces, the absence of other negative expressions, such as sad faces, precludes knowing whether activation differences between offspring at high- and low-risk for MDD are specific to fear stimuli or occur across negative emotions. If effects were selective to fear, it would provide evidence of specific perturbations. Another limitation concerns the inclusion of offspring with a history of anxiety. However, since anxiety disorders are common in offspring of MDD parents, excluding past anxiety would have reduced representativeness of the sample, thereby decreasing the generalizability of the findings. At the same time, the frequent occurrence of anxiety disorders in the high-risk group may limit clear interpretation of findings. In this study, lifetime anxiety disorders did not account for differences between juveniles at high and low risk for MDD (Supplement Table 2), indicating that group differences in activation were a function of MDD risk status, and were not related to the presence of anxiety disorders. In addition, the present study was not designed to address developmental changes in brain function and how they interact with risk for psychopathology. It will be important for future studies to characterize the role of the amygdala and NAcc from a developmental perspective as well as in relation to vulnerability for mood disorders. Finally, it was not possible to determine whether group differences in brain function were mediated by differential attention to specific facial expressions. Nevertheless, the findings document that each group showed increases to some stimuli and decreases to others during passive 
viewing. These results are inconsistent with the possibility that one group failed to attend during passive viewing.

\section{Future Directions}

First, replication is necessary. It will be particularly important to study larger samples of children at risk for MDD with and without anxiety to examine the contribution of anxiety disorders to neural perturbations in at-risk individuals. Second, the inclusion of multiple negative emotional stimuli, such as sad and angry faces, would inform on the specific significance of emotional stimuli. Third, while offspring of parents with MDD are at greater risk for MDD, they are also at increased risk for other mental disorders, especially anxiety disorders ${ }^{1}$. Thus, the present findings may not relate to MDD risk specifically. Longitudinal studies would inform this question, and also whether variations in neural activation predict the incidence of MDD among those at high risk. Such work could eventually identify which of the at-risk individuals are at highest risk for MDD and other psychopathology. For example, individuals with the highest activation in a given structure or a particular neural interaction profile might be those at highest risk. If so, the study of prevention efforts would be especially appropriate in this subgroup of at risk individuals. Fourth, the study of eye movements might identify patterns of gaze that enhance brain activation in high- vs. low-risk subjects during passive viewing. 


\section{References}

1. Weissman MM, Wickramaratne $P$, Nomura $Y$, Warner V, Pilowsky D, Verdeli H: Offspring of depressed parents: 20 years later. Am J Psychiatry 2006; 163:10018

2. Pine DS, Cohen P, Gurley D, Brook J, Ma Y: The risk for early-adulthood anxiety and depressive disorders in adolescents with anxiety and depressive disorders. Arch Gen Psychiatry 1998; 55:56-64

3. Nestler EJ, Carlezon WA, Jr.: The mesolimbic dopamine reward circuit in depression. Biol Psychiatry 2006; 59:1151-9

4. Nolen-Hoeksema S, Parker LE, Larson J: Ruminative coping with depressed mood following loss. J Pers Soc Psychol 1994; 67:92-104

5. Gotlib IH, Kasch KL, Traill S, Joormann J, Arnow BA, Johnson SL: Coherence and specificity of information-processing biases in depression and social phobia. J Abnorm Psychol 2004; 113:386-98

6. Ladouceur CD, Dahl RE, Williamson DE, Birmaher B, Axelson DA, Ryan ND, Casey BJ: Processing emotional facial expressions influences performance on a Go/NoGo task in pediatric anxiety and depression. J Child Psychol Psychiatry 2006; 47:1107-15

7. Murphy FC, Sahakian BJ, Rubinsztein JS, Michael A, Rogers RD, Robbins TW, Paykel ES: Emotional bias and Inhibitory control processes in mania and depression. Psychol Med 1999; 29:1307-1321

8. Sloan DM, Strauss ME, Wisner KL: Diminished response to pleasant stimuli by depressed women. J Abnorm Psychol 2001; 110:488-93

9. Whalen PJ, Rauch SL, Etcoff NL, McInerney SC, Lee MB, Jenike MA: Masked presentations of emotional facial expressions modulate amygdala activity without explicit knowledge. J Neurosci 1998; 18:411-418

10. Hariri AR, Bookheimer SY, Mazziotta JC: Modulating emotional responses: effects of a neocortical network on the limbic system. Neuroreport 2000; 11:4348

11. Monk CS, McClure EB, Nelson EE, Zarahn E, Bilder RM, Leibenluft E, Charney DS, Ernst M, Pine DS: Adolescent Immaturity in Attention-Related Brain Engagement to Emotional Facial Expressions. Neuroimage 2003; 20:420-428

12. Phelps EA, O'Connor KJ, Gatenby JC, Gore JC, Grillon C, Davis M: Activation of the left amygdala to a cognitive representation of fear. Nat Neurosci 2001; 4:43741. 
13. Yang TT, Menon V, Reid AJ, Gotlib IH, Reiss AL: Amygdalar activation associated with happy facial expressions in adolescents: a 3-T functional MRI study. J Am Acad Child Adolesc Psychiatry 2003; 42:979-85

14. Ernst M, Nelson EE, Jazbec S, McClure EB, Monk CS, Leibenluft E, Blair J, Pine DS: Amygdala and nucleus accumbens in response to receipt and omission of gains in adults and adolescents. Neuroimage 2005; 25:1279-91

15. Ernst M, Nelson EE, McClure EB, Monk CS, Munson S, Eshel N, Zarahn E, Leibenluft E, Zametkin A, Towbin K, Blair J, Charney D, Pine DS: Choice selection and reward anticipation: an fMRI study. Neuropsychologia 2004; 42:1585-97

16. Kelley $A E$ : Ventral striatal control of appetitive motivation: role in ingestive behavior and reward-related learning. Neurosci Biobehav Rev 2004; 27:765-76

17. Knutson B, Adams CM, Fong GW, Hommer D: Anticipation of increasing monetary reward selectively recruits nucleus accumbens. J Neurosci 2001; 21:RC159

18. May JC, Delgado MR, Dahl RE, Stenger VA, Ryan ND, Fiez JA, Carter CS: Event-related functional magnetic resonance imaging of reward-related brain circuitry in children and adolescents. Biol Psychiatry 2004; 55:359-66

19. Reynolds SM, Berridge KC: Positive and negative motivation in nucleus accumbens shell: bivalent rostrocaudal gradients for GABA-elicited eating, taste "liking"/"disliking" reactions, place preference/avoidance, and fear. J Neurosci 2002; 22:7308-20

20. Schultz W: Neural coding of basic reward terms of animal learning theory, game theory, microeconomics and behavioural ecology. Curr Opin Neurobiol 2004; $14: 139-47$

21. Sheline YI, Barch DM, Donnelly JM, Ollinger JM, Snyder AZ, Mintun MA: Increased amygdala response to masked emotional faces in depressed subjects resolves with antidepressant treatment: an fMRI study. Biol Psychiatry 2001; $50: 651-8$

22. Surguladze S, Brammer MJ, Keedwell P, Giampietro V, Young AW, Travis MJ, Williams SC, Phillips ML: A differential pattern of neural response toward sad versus happy facial expressions in major depressive disorder. Biol Psychiatry 2005; 57:201-9

23. Thomas KM, Drevets WC, Dahl RE, Ryan ND, Birmaher B, Eccard CH, Axelson $D$, Whalen PJ, Casey BJ: Amygdala response to fearful faces in anxious and depressed children. Arch Gen Psychiatry 2001; 58:1057-63. 
24. Roberson-Nay R, McClure EB, Monk CS, Nelson EE, Guyer AE, Fromm SJ, Charney DS, Leibenluft E, Blair J, Ernst M, Pine DS: Increased Amygdala Activity During Successful Memory Encoding in Adolescent Major Depressive Disorder: An fMRI Study. Biol Psychiatry 2006

25. Fu CH, Williams SC, Cleare AJ, Brammer MJ, Walsh ND, Kim J, Andrew CM, Pich EM, Williams PM, Reed LJ, Mitterschiffthaler MT, Suckling J, Bullmore ET: Attenuation of the neural response to sad faces in major depression by antidepressant treatment: a prospective, event-related functional magnetic resonance imaging study. Arch Gen Psychiatry 2004; 61:877-89

26. Forbes EE, May JC, Siegle GJ, Ladouceur CD, Ryan ND: Reward- Related Decision-Making in Pediatric Anxiety and Major Depressive Disorders: An fMRI Study. Journal of Child Psychiatry and Psychology 2006; 47:1031-1040

27. Caspi A, Sugden K, Moffitt TE, Taylor A, Craig IW, Harrington H, McClay J, Mill J, Martin J, Braithwaite A, Poulton R: Influence of life stress on depression: moderation by a polymorphism in the 5-HTT gene. Science 2003; 301:386-9

28. Hariri AR, Mattay VS, Tessitore A, Kolachana B, Fera F, Goldman D, Egan MF, Weinberger DR: Serotonin transporter genetic variation and the response of the human amygdala. Science 2002; 297:400-3

29. Blair RJR, Morris JS, Frith CD, Perrett DI, Dolan RJ: Dissociable neural responses to facial expressions of sadness and anger. Brain 1999; 122:883-893

30. Hariri AR, Drabant EM, Munoz KE, Kolachana BS, Mattay VS, Egan MF, Weinberger DR: A susceptibility gene for affective disorders and the response of the human amygdala. Arch Gen Psychiatry 2005; 62:146-52

31. Whalen PJ, Shin LM, McInerney SC, Fischer H, Wright Cl, Rauch SL: A functional MRI study of human amygdala responses to facial expressions of fear versus anger. Emotion 2001; 1:70-83

32. Taylor SF, Phan KL, Decker LR, Liberzon I: Subjective rating of emotionally salient stimuli modulates neural activity. Neuroimage 2003; 18:650-9

33. Pine DS, Klein RG, Mannuzza S, Moulton JL, 3rd, Lissek S, Guardino M, Woldehawariat G: Face-emotion processing in offspring at risk for panic disorder. J Am Acad Child Adolesc Psychiatry 2005; 44:664-72

34. Spitzer RL, Williams JB, Gibbon M, First MB: The Structured Clinical Interview for DSM-III-R (SCID). I: History, rationale, and description. Arch Gen Psychiatry 1992; 49:624-9.

35. Kentgen LM, Klein RG, Mannuzza S, Davies M: Test-retest reliability of maternal reports of lifetime mental disorders in their children. J Abnorm Child Psychol $1997 ; 25: 389-98$ 
36. Burgund ED, Kang HC, Kelly JE, Buckner RL, Snyder AZ, Petersen SE, Schlaggar BL: The feasibility of a common stereotactic space for children and adults in fMRI studies of development. Neuroimage 2002; 17:184-200.

37. Rossion B, Schiltz C, Robaye L, Pirenne D, Crommelinck M: How does the brain discriminate familiar and unfamiliar faces?: a PET study of face categorical perception. J Cogn Neurosci 2001; 13:1019-34

38. Worsley KJ, Marrett S, Neelin P, Vandal AC, Friston KJ, Evans AC: A unified statistical approach for determining significant signals in images of cerebral activation. Hum Brain Mapp 1996; 4:58-73

39. Fischer $\mathrm{H}$, Wright $\mathrm{Cl}$, Whalen PJ, Mclnerney SC, Shin LM, Rauch SL: Brain habituation during repeated exposure to fearful and neutral faces: A functional MRI study. Brain Res Bull 2003; 59:387-92 


\section{Figure Captions}

Figure 1: $F$ test indicating group differences in activation as a function of facial expression and attention condition. Figure $1 \mathrm{~A}$ illustrates bilateral activation in the amygdala, and Figure 1B depicts bilateral activation in the NAcc. Images are masked with the ROls to better characterize activation within the amygdala and NAcc. Figures 1 and 2 display group-level data superimposed on the high-resolution, MNI-normalized anatomical image provided in SPM2.

Figure 2: Group differences for juveniles at high risk for MDD vs. low-risk comparisons in amygdala (Figure 2A) and NAcc (Figure 2B) for activation within the passive viewing condition ( $t$ test).

Figure 3: Activation in the high-risk and low-risk offspring within the passive viewing condition. This figure illustrates that high-risk juveniles relative to low-risk comparisons evidenced increased amygdala and NAcc activation to fearful faces and decreased NAcc activation to happy faces. Values are represented as percent signal change and are relative to the neutral face trials. Values were derived from the mean of a $4 \mathrm{~mm}$ sphere around the peak activation within the linear trend analysis that examined increasing activation as the faces changed from happy to fearful. To reduce noise, face trials were averaged together as follows: $100 \%$ and $75 \%$ happy, $50 \%$ and $25 \%$ happy, $25 \%$ and $50 \%$ fear, and $75 \%, 100 \%$ and exaggerated fear. Coordinates are presented in Table 1B. 
Table 1A. $F$ test of group contrasts in activation peaks as a function of facial expression and attention condition ( $\mathrm{MNI}$ coordinates, $\mathrm{x}, \mathrm{y}, \mathrm{z}$ in $\mathrm{mm}$ ).

\begin{tabular}{|l|l|l|l|l|l|l|}
\hline Region & Cluster Size (voxels) & $\mathrm{x}$ & $\mathrm{y}$ & $\mathrm{z}$ & $F(2,74)$ & $p$ \\
\hline Left Amygdala & 161 & -18 & 0 & -14 & 6.19 & 0.03 \\
\hline Right Amygdala & 96 & 34 & -6 & -12 & 5.56 & 0.04 \\
\hline Left NAcc & 118 & -4 & 10 & 2 & 9.60 & 0.003 \\
\hline Right NAcc & 154 & 8 & 12 & 2 & 9.18 & 0.004 \\
\hline
\end{tabular}

Table 1B. Voxels of significant activation between high-risk and low-risk offspring within passive viewing to more fearful faces based on the linear trend analysis (MNI coordinates, $x, y, z$ in $\mathrm{mm}$ ). Differences indicate greater activation in the high- relative to the low-risk offspring.

\begin{tabular}{|l|l|l|l|l|l|l|}
\hline Region & Cluster Size (voxels) & $\mathrm{x}$ & $\mathrm{y}$ & $\mathrm{Z}$ & $t(37)$ & $p$ \\
\hline Left Amygdala & 180 & -18 & 2 & -14 & 3.12 & 0.014 \\
\hline Right Amygdala & 158 & 20 & -4 & -12 & 2.62 & 0.038 \\
\hline Left NAcc & 172 & -4 & 10 & 2 & 3.85 & 0.002 \\
\hline Right NAcc & 155 & 8 & 16 & 4 & 4.07 & 0.001 \\
\hline
\end{tabular}

Table 1C. Group differences in activation during passive viewing of the non-chimeric faces (100\% fear, neutral, $100 \%$ happy) based on post-hoc $t$-tests of the peak activation voxels depicted in Table 1B.

\begin{tabular}{|c|c|c|c|c|c|c|c|c|}
\hline \multirow{3}{*}{$\frac{\text { High Risk vs. Low Risk }}{100 \% \text { fear vs. neutral }}$} & \multicolumn{2}{|c|}{ Left Amygdala } & \multicolumn{2}{|c|}{ Right Amygdala } & \multicolumn{2}{|c|}{ Left NAcc } & \multicolumn{2}{|c|}{ Right NAcC } \\
\hline & \multicolumn{2}{|c|}{$t \quad p$} & \multirow{2}{*}{\multicolumn{2}{|c|}{\begin{tabular}{r|r}
$t$ & $p$ \\
200 & 002
\end{tabular}}} & \multirow{2}{*}{$\frac{t}{2.65}$} & \multirow{2}{*}{$\frac{p}{006}$} & \multirow{2}{*}{$\frac{t}{2.54}$} & \multirow{2}{*}{$\begin{array}{c}p \\
.008\end{array}$} \\
\hline & 2.72 & .005 & & & & & & \\
\hline Low Risk vs. High Ris & & & & & & & & \\
\hline $100 \%$ happy vs neutral & 0.38 & .30 & .23 & .34 & 1.83 & .037 & 1.75 & .043 \\
\hline
\end{tabular}


Table 2a. Interaction analysis of passive viewing and subjective fear for the high-risk offspring. (In the same analysis with the low-risk juveniles alone, no differences were found.)

\begin{tabular}{|l|l|l|l|l|l|l|}
\hline Region & Cluster Size (voxels) & $\mathrm{x}$ & $\mathrm{y}$ & $\mathrm{z}$ & $t(37)$ & $p$ \\
\hline Left Amygdala & 185 & -24 & 4 & -18 & 2.65 & .018 \\
\hline Right Amygdala & 168 & 22 & 2 & -18 & 2.41 & .053 \\
\hline Left NAcc & 60 & -4 & 10 & 2 & 2.95 & .018 \\
\hline Right NAcc & 150 & 8 & 12 & 2 & 2.69 & .029 \\
\hline
\end{tabular}

Table $2 \mathrm{~b}$. Interaction analysis of passive viewing and nose width for the high-risk subjects. (For low-risk juveniles alone, no differences were found in this comparison).

\begin{tabular}{|l|l|l|l|l|l|l|}
\hline Region & Cluster Size (voxels) & $\mathrm{x}$ & $\mathrm{y}$ & $\mathrm{z}$ & $t(37)$ & $p$ \\
\hline Left Amygdala & 215 & -18 & 2 & -14 & 3.38 & .009 \\
\hline Right Amygdala & 181 & 22 & 0 & -12 & 3.06 & .04 \\
\hline Left NAcc & 171 & -2 & 14 & 8 & 3.77 & .003 \\
\hline Right NAcc & 147 & 8 & 16 & 4 & 3.02 & .017 \\
\hline
\end{tabular}

Table 2c. Interaction analysis directly comparing the high-risk and low-risk offspring for passive viewing and subjective fear.

\begin{tabular}{|l|l|l|l|l|l|l|}
\hline Region & Cluster Size (voxels) & $\mathrm{x}$ & $\mathrm{y}$ & $\mathrm{z}$ & $t(37)$ & $p$ \\
\hline Left Amygdala & 120 & -12 & -6 & -10 & 2.57 & .042 \\
\hline Right Amygdala & 8 & 20 & -6 & -12 & 1.79 & .142 \\
\hline Left NAcc & 46 & -4 & 10 & 2 & 2.84 & .024 \\
\hline Right NAcc & 134 & 8 & 12 & 2 & 2.75 & .026 \\
\hline
\end{tabular}

Table 2d. Interaction analysis directly comparing the high-risk and low-risk offspring for passive viewing and nose width rating.

\begin{tabular}{|l|l|l|l|l|l|l|}
\hline Region & Cluster Size (voxels) & $\mathrm{x}$ & $\mathrm{y}$ & $\mathrm{z}$ & $t(37)$ & $p$ \\
\hline Left Amygdala & 66 & -20 & 2 & -12 & 2.9 & .026 \\
\hline Right Amygdala & 29 & 34 & -6 & -12 & 3.17 & .015 \\
\hline Left NAcc & 137 & -2 & 14 & 8 & 4.03 & .002 \\
\hline Right NAcc & 141 & 8 & 16 & 4 & 3.73 & .003 \\
\hline
\end{tabular}


Figure 1.

A.

B.
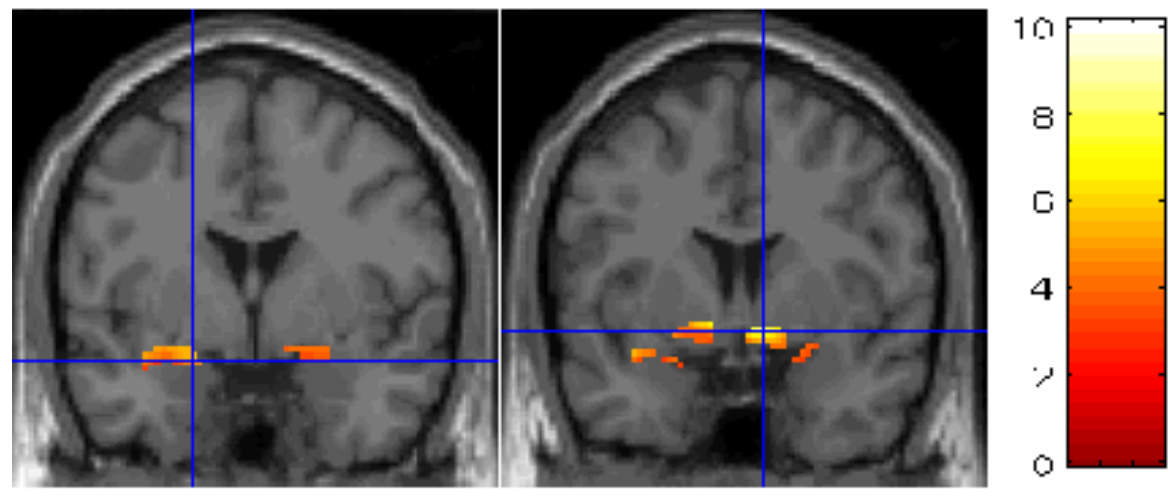
Figure 2.

A.

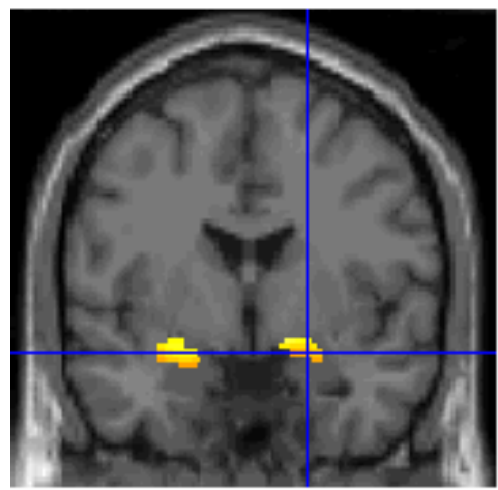

B.

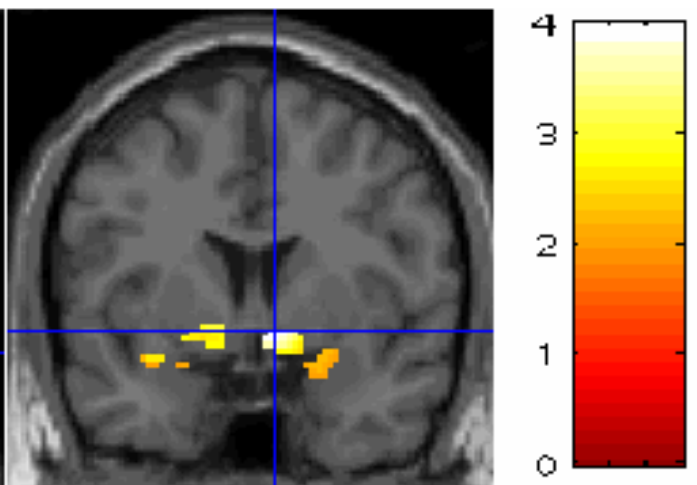


Figure 3.

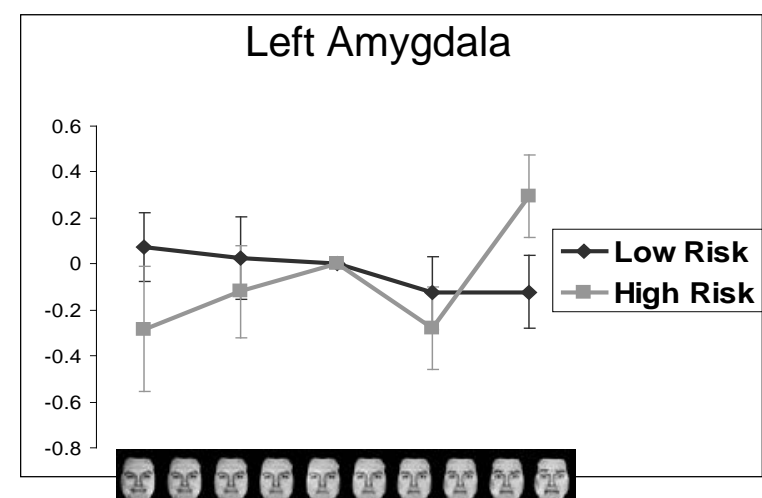

Happy Neutral Fearful

Left NAcc

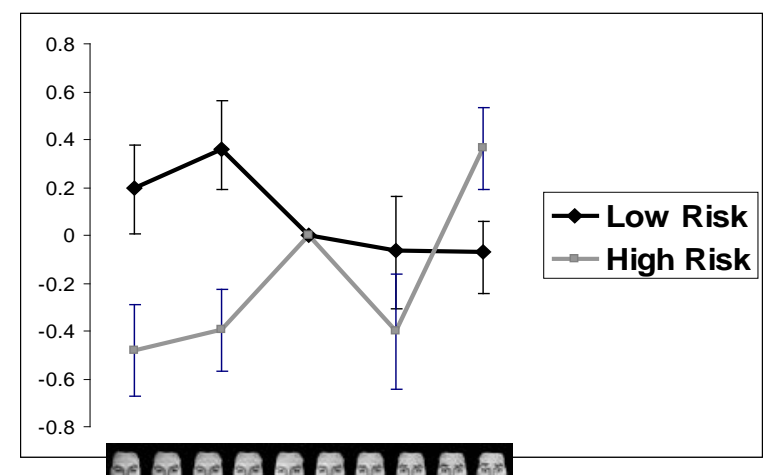

30000000

Happy
Neutral

Fearful

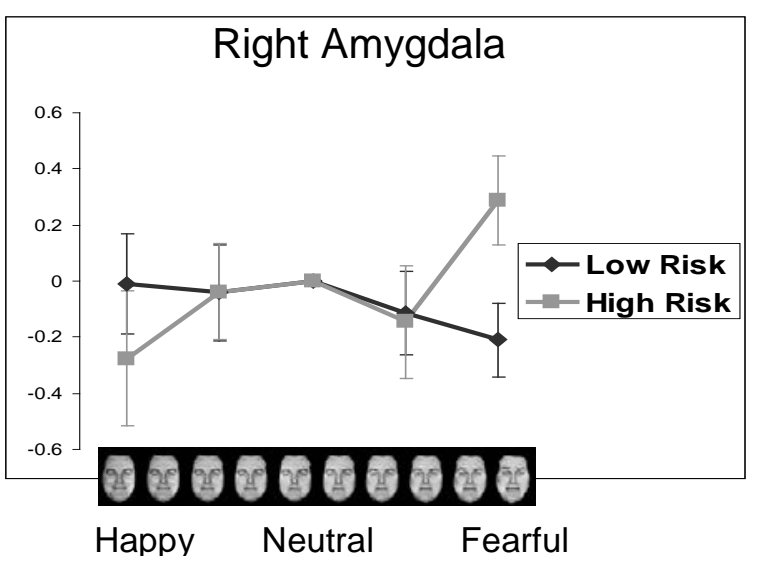

Right NAcc

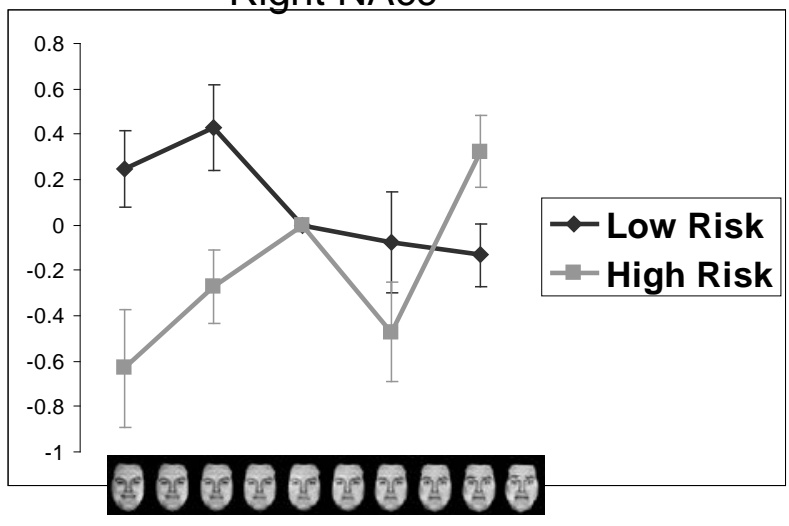

Happy

Neutral

Fearful 